\title{
Geometric and Artistic Graphics
}

Design Generation with Microcomputers 
Other Macmillan titles of related interest

Advanced Graphics with the IBM Personal Computer

Ian O. Angell

Advanced Graphics with the Acorn Electron

Ian O. Angell and Brian J. Jones

Advanced Graphics with the BBC Model B Microcomputer

Ian O. Angell and Brian J. Jones

Advanced Graphics with the Sinclair ZX Spectrum

Ian O. Angell and Brian J. Jones

Sorting Routines for Microcomputers

Angus Barber and Keith McKluckie

Spatial Structure and the Microcomputer

A. N. Barrett and A. L. Mackay

Assembly Language Programming for the BBC Microcomputer

(second edition)

Ian Birnbaum

Using Your Home Computer (Practical Projects for the Micro Owner) Garth W.P.Davies

Micro-Maths

Keith Devlin

The Purple Planet: Micro-PROLOG for the Spectrum $48 \mathrm{~K}$ Serafim Gascoigne

Turtle Fun: LOGO for the Spectrum $48 \mathrm{~K}$

Serafim Gascoigne

Practical BASIC Programming

Peter Gosling

Program Your Microcomputer in BASIC

Peter Gosling

A Science Teacher's Companion to the BBC Microcomputer

Philip Hawthorne

Programming in Z80 Assembly Language

Roger Hutty

Operating the BBC Microcomputer: A Concise Guide

Graham Leah

Beginning BASIC with the ZX Spectrum

Judith Miller

The Commodore 64 in Action: Sound Graphics and Filing

M. M. Novak

Graphics with the Commodore 128

M. M. Novak

Using Sound and Speech on the BBC Microcomputer Martin Phillips

$A$ Beginner's Guide to Interfacing the BBC Microcomputer Martin Phillips

A Complete Disk Manual for the BBC Microcomputer R. Sadek

File Handling on the BBC Microcomputer

Brian J. Townsend

Computer Literacy: A beginners' guide Vincent Walsh

Good BASIC Programming on the BBC Microcomputer Margaret White 


\title{
Geometric and Artistic Graphics
}

\section{Design Generation with Microcomputers}

\author{
Jean-Paul Delahaye
}

Professor, University of Lille

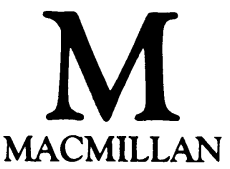


() Editions EYROLLES, 1985

Authorised English Language edition of Dessins Géométriques et Artistiques avec votre Micro-ordinateur by Jean-Paul Delahaye, first published 1985 by Éditions EYROLLES, 61 Boulevard Saint-Germain, 75005 Paris

Translated by J. Finegold and M. J. Stewart

(c) English Language edition, Macmillan Education Ltd, 1986

All rights reserved. No reproduction, copy or transmission of this publication may be made without written permission.

No paragraph of this publication may be reproduced, copied or transmitted save with written permission or in accordance with the provisions of the Copyright Act 1956 (as amended).

Any person who does any unauthorised act in relation to this publication may be liable to criminal prosecution and civil claims for damages.

First published 1986

Published by

MACMILLAN EDUCATION LTD

Houndmills, Basingstoke, Hampshire RG21 2XS

and London

Companies and representatives throughout the world

British Library Cataloguing in Publication Data

Delahaye, Jean-Paul

Geometric \& Artistic Graphics

1. Computer graphics 2. BASIC (Computer program language)

I. Title 2. Dessins geometriques et artistiques avec votre

micro-ordinateur. English

$0006.6 ' 76 \quad T 385$

ISBN 978-0-333-41799-7 ISBN 978-1-349-08770-9 (eBook)

DOI 10.1007/978-1-349-08770-9 


\section{Contents}

Preface vi

Introduction vii

1 Regular Polygons, Stars etc 1 REGULAR POLYGONS 1 REGULAR STARS

COMPOSITION 1 8

COMPOSITION 2

JOLYGONS 20

2 Designs Using Data 25

HORSE 26

LIONS and FLYING FISH 37

3 Folded Paper Dragons 41

DRAGONS 43

4 Fractal Stars $\quad 55$

5 Curves $\quad 64$

ORBITAL CURVES $\quad 64$

TWISTING CURVES

SPIRAL CURVES 81

6 Line Drawings $\quad 85$

COMPLETE BIPARTITE GRAPH

MODULO LINES 90

LINEAR STICKS $\quad 96$

7 Simple Fractals 100

SIMPLE FRACTALS 100

SIMPLE ROUNDED FRACTALS 117

SIMPLE DEFORMED FRACTALS 127

8 Elastic Grids 139

9 Drawing Surfaces $\quad 147$

10 The Third Dimension 168

D3DATA 170

D3CUBE 175

D3STRUCTURES 185

Appendix: Some Program Adaptations 205

References and Bibliography 209 


\section{Preface}

Drawing interesting and striking pictures with a microcomputer is not difficult. This book shows you how.

The book can be used in two ways. The first way is simply to key in the programs for the designs that appeal to you; they can then be displayed on your monitor or be plotted out as hard copy.

The second way is to learn how the programs work by studying the accompanying explanations, so that using the example drawings as a starting point you can invent and develop your own designs. All the examples have been selected with this aim in view; even minor modifications to the programs will give a wide variety of variations. With some patience and imagination the reader will quickly learn how to draw his own geometric and artistic shapes.

No previous knowledge of BASIC or mathematics is required for the user who adopts the first method, and even if you adopt the second, the author has included sufficient background information along with the explanations of the programs.

The range of examples has been chosen in order to appeal to a wide range of individual tastes. The length of the programs has been restricted so that no project should take more than half an hour at most to complete. The basic concepts are rarely complicated even though some of the spectacular results might lead one to think so.

The selected algorithms are always the simplest and the programs do not require more than $8 \mathrm{~K}$ of live memory. This sometimes results in longer execution times and problems with screen display. However, making the necessary refinements and modifications provide the reader with valuable exercises in programming.

Above all, though, the author's aim is to show you how to develop your own individual graphics skills.

The publishers are grateful to Dr I. O. Angell for his kind assistance in the preparation of the English-language edition of this work. 


\section{Introduction}

\section{HOW TO USE THE PROGRAMS}

\section{Universal Application}

All the programs included in this book have been written in Microsoft BASIC. A very simple approach has been adopted in writing them, thus permitting their use on virtually any modern microcomputer if the simple modifications indicated in section 4 of this chapter are applied.

The routines can all be programmed on computers having the most modest graphics facilities, either to obtain a display on the screen or, if an appropriate graphics printer or plotter is attached, to obtain a hard copy printout.

The listings in the book have been taken from a Canon X 07, which was interfaced to a Canon X 710 plotter. Readers who own such a system can

GOTO Chapter 1

ENTER the listings

RUN .

\section{Presentation of the programs}

All of the program listings have at line 50

* initialisation routines for the printer/plotter

* the variable NP, representing the Number of Pixels available.

The Canon X 710, which was used for the hard copies shown in the book, has a maximum number of 480 plotting positions available. To customise the programs for your own system, modify the value given to NP such that NP becomes equal to the lower of the two resolution values of your display, less l. For example, with a display capable of a resolution of $320 \times 256$, the value of 255 must be assigned to the variable NP.

* a calculation to generate a relatively precise value for $\mathrm{PI}$ : $\mathrm{PI}=\mathrm{ATN}(1) * 4$. Note that on many computers this formula will either prove unnecessary (as on the $\mathrm{BBC}$ microcomputer) or may have to be modified. 
It is recommended that users add their own line 10 to each program, which should be a REM statement identifying the program or modification.

\section{Screen Window}

The majority of the programs generate their design in a square (called a "window") within which each point may be identified by two values (called "coordinates"). Usually these coordinates will be as indicated in the following diagram, where $X$ has a value between 0 and NP and where $Y$ also has a value between 0 and NP.



Sometimes, however, a larger window is used, with $\mathrm{X}$ taking a value between 0 and $N P$, and $Y$ having a value either between 0 and 2 * NP or between $-\mathrm{NP}$ and +NP

If you encounter problems in generating effective windows or develop deformed displays, one of the following routines should remedy the situation:

In the graphic commands, replace the expression $X, Y$ by

$\mathrm{X}, \mathrm{Y}+\mathrm{DE}$ to move the design $\mathrm{DE}$ pixels higher. (Note that if $D E$ has a negative value, then the design will move $D E$ pixels lower)

$\mathrm{X}, \mathrm{CE}$ * $\mathrm{Y}$ to "squash" the design vertically; $\mathrm{CE}$ should have a value of less than 1 , typically $C E=0.8$ or 0.9

$C E * X, Y$ to "squeeze" the design horizontally, where $C E$ has a value less than 1

$C E * X, C E * Y$ to generate a smaller design (if $C E$ has a value less than 1 )

or to generate a larger design (if $\mathrm{CE}$ has a value greater than 1 ) 
$X, N P-Y$ to invert the design. All of the programs in this book assume a screen origin at the bottom left-hand corner of the screen. However, as some computers fix the origin as being the top left-hand corner, you may need to reverse the design. Note that for many symetric geometric figures there will be no virtue in so doing.

It is suggested that you assign values to the variables $C E$ and $D E$ at the beginning of the program, ideally in line 50 .

In order to speed up programs which would otherwise execute extremely slowly - owing to the large number of calculations required - routines in the book deliberately omit any verification routines. An example of such routines would be a check to prevent any part of a design falling outside of the allocated window. Similarly, there has been no attempt to automatically centre a design in its window. Readers who wish to do no more than create a design - and who do not wish to plumb the depths of the programming logic - will not be inconvenienced, as all of the routines generate perfectly acceptable designs. However, readers who wish to use the programs as a stepping stone to develop their own programming ability and to create their own designs may wish to incorporate appropriate control and verification routines to obtain, for example, centred displays.

\section{Modification of the Graphics Commands}

In order to facilitate any subsequent modification of the programs to run on different machines, only two graphics commands have been used throughout the book:

Command 1 move to coordinate $X, Y$

Command 2 draw a line from the last point to the new coordinate point $X, Y$

For the Canon X 07 connected to the Canon X 710 plotter, this takes the form

Command 1 LPRINT "M"; $; ; ", "$; Y

Command 2 LPRINT "D"; $X ; ", "$;

For the BBC Microcomputer this should be expressed as

Command 1 MOVE $X, Y$

Command 2 DRAW $X, Y$ 
Computers which cannot accept a 'MOVE' command in the form of Command 1 may require an alternative Command:

Command 3 draw a line between coordinates (Xl, Yl) and $(\mathrm{X} 2, \mathrm{Y} 2)$.

This command would be expressed as

a. For the Epson HX20; Sharp PC 1500, T 07, M 05, MZ80-B;NEC PC8001; Dragon 64;MSX computers:

$\operatorname{LINE}(\mathrm{X} 1, \mathrm{Y} 1)-(\mathrm{X} 2, \mathrm{Y} 2)$

b. For the DAI; Tandy and Sinclair spectrum computers: $\operatorname{DRAW}(\mathrm{X} 1, \mathrm{Y} 1)-(\mathrm{X} 2, \mathrm{Y} 2)$

c. For Wang computers:

$\operatorname{PLOT}(\mathrm{X} 1, \mathrm{Y} 1)-(\mathrm{X} 2, \mathrm{Y} 2)$

d. For the Apple II (High Resolution) Computer:

HPLOT X1,Y1 TO X2,Y2

With this one command, it is, in fact, possible to replace the two previous commands:

Command 1 becomes : $\mathrm{XW}=\mathrm{X}: \mathrm{YW}=\mathrm{Y}$

Command 2 is replaced by command 3 (as appropriate for the machine) and followed by $(X W, Y W)-(X, Y): X W=X: Y W=Y$

(An example of a program modification using this routine may be found in the appendix - Star Fractals for the Apple II.)

Note that none of the programs in this book utilise colour; should you wish to add colour, it is only necessary to add the appropriate colour commands for your own computer.

Note also that certain programs can be considerably simplified if you have high level graphics commands, such as CIRCLE, available.

\section{IF . . . THEN . . ELSE}

If your computer does not support the construction IF condition THEN action 1 ELSE action 2

you may modify any programs containing such a line in the following way:

$\begin{array}{ll}<\text { Line Number } & \begin{array}{l}\text { IF condition THEN action } 1: \text { GOTO } \\ <\text { Line number }+2>\end{array} \\ <\text { Line Number }+1> & \text { action } 2 \\ <\text { Line number }+2> & \text { REM }\end{array}$


For example:

200 IF $A=0$ THEN $A=B$ ELSE $A=C$

would become:

200 IF $A=0$ THEN $A=B$ : GOTO 202

$201 \mathrm{~A}=\mathrm{C}$

202 REM

\section{Original and Modified Programs}

In order to avoid unneccessary repetition of programs which are only slightly different, the 'master' program is displayed only once, and subsequent modifications are shown simply by indicating the line(s) which have been changed. This has the added advantage that the changes or modifications are more immediately appreciated. In most cases, modification is made simply to one or more of the parameters which each 'master" program contains.

In order to obtain the greatest benefit from this book, do try to follow how the programs and subsequent modifications work. The explanations given with each program will provide substantial assistance. By understanding how the programs have been constructed you will be in a position to create your own, original - and, sometimes, completely unexpected! - designs, and you will find yourself engrossed in the world of Computer Art.

\section{Translator's Note}

Because this book was originally written in French, many of the variable names were chosen as having some significance or relevance which is not immediately apparent to the English-speaking reader. Do check your keying carefully, ensuring that you differentiate between $I$ and 1,0 and $O$ and $Q$, etc. If you make changes to the variable names, do ensure that these changes are maintained when keying in the modifications. 